\title{
Pengolahan Limbah Cair Domestik dengan Tanaman Eceng Gondok (Eichornia Crassipes) untuk Menghasilkan Air Bersih di Perumahan Green Tombro Kota Malang
}

\author{
Anita Rahmawati, Warsito \\ Program Studi Teknik Sipil Universitas Islam Malang, Kota Malang, Indonesia \\ Email: ar.nita.rachma@gmail.com,warsito@gmail.com
}

Received 28 Februari 2020 | Revised 30 April 2020 | Accepted 22 Mei 2020

\begin{abstract}
ABSTRAK
Hampir semua pemukiman di Indonesia khususnya di Kota Malang membuang limbah hasil aktivitas cuci, mandi, dan dapur langsung ke saluran pembuangan air tanpa diolah terlebih dahulu, sehingga menimbulkan bau tak sedap dan menimbulkan berbagai penyakit. Sebelum air limbah dibuang ke badan air, ataupun dimanfaatkan kembali untuk kebutuhan irigasi, maka air limbah tersebut perlu ditampung dan diolah terlebih dahulu. Metode yang digunakan dalam penelitian ini menggunakan metode filtrasi dan pemanfaatan tanaman eceng gondok (eichornia crassipes) sebagai media penyerap polutan limbah cair domestik. Karakteristik limbah cair domestik sebelum terjadi pengolahan di Perumahan Green Tombro Kota Malang yaitu memiliki pH =9, kandungan COD sebesar 296,45 mg/l, dan kandungan BOD sebesar 14,813 mg/l, Sedangkan setelah mengalami proses pengolahan, karakteristik limbah cair domestik memiliki $\mathrm{pH}=7$ (dikatakan netral), kandungan COD sebesar 296,45 mg/l dan kandungan BOD sebesar 80,85 mg/l, yang berarti sudah memenuhi ketentuan baku mutu air limbah cair domestik yang mengacu pada peraturan Menteri Lingkungan Hidup dan Kehutanan Indonesia No. P.68/Menlhk/Setjen/Kum.1/8/2016.
\end{abstract}

Kata kunci: limbah cair domestik, fitoremediasi, eceng gondok (eichornia crassipes)

\begin{abstract}
Almost all settlements in Indonesia, especially in the city of Malang, dispose waste from washing, bathing, and kitchen activities directly into the water bodies without being processed first. In the long term, the results of this cause odor and cause various diseases. Before wastewater is discharged into water bodies, or reused for irrigation purposes, the waste water needs to be collected and treated. The method used in this study was a filtration method and utilization of water hyacinth plants (Eichornia crassipes) as a pollutant absorber for domestic waste. Before treatment, domestic wastewater in Green Tombro Housing, Malang City has a $\mathrm{pH}=9$, a COD of $296.45 \mathrm{mg} / \mathrm{l}$, and a BOD of $14.813 \mathrm{mg} / \mathrm{l}$, whereas after undergoing treatment, the domestic liquid waste has a $\mathrm{pH}=7$ (said to be neutral), a COD content of $296.45 \mathrm{mg} / \mathrm{l}$ and a BOD content of $80.85 \mathrm{mg} / \mathrm{l}$, which means that it meets the quality standards of domestic liquid waste water refering to the regulation of the Minister of Environment and Forestry of Indonesia No. P.68 / Menlhk / Setjen / Kum. 1 / 8/2016.
\end{abstract}

Keywords: domestic liquid waste, phytoremediation, water hyacinth (Eichornia crassipes) 


\section{PENDAHULUAN}

Pencemaran limbah cair merupakan perubahan fisik air baik secara langsung maupun tidak langsung yang sifatnya berbahaya atau berpotensi menyebabkan penyakit atau gangguan bagi keberlangsungan kehidupan makhluk hidup. Perubahan langsung dan tidak langsung ini ditunjukkan dengan perubahan fisik, kimia, biologi atau radioaktif. Sedangkan kualitas air termasuk salah satu faktor yang menentukan kesejahteraan manusia. Secara umum, penyebab pencemaran air berdasarkan sumbernya dapat dikategorikan sebagai sumber kontaminasi langsung dan tidak langsung [1].

Tanaman Eceng Gondok (Eichhornia crassipes) merupakan salah satu jenis tumbuhan air yang mengapung dan biasanya sering dimanfaatkan sebagai tanaman air penyerap polutan. Eceng gondok pertama kali ditemukan secara tidak sengaja oleh seorang ilmuwan bernama Carl Friedrich Philipp von Martius, seorang ahli botani berkebangsaan Jerman pada tahun 1824 ketika sedang melakukan ekspedisi di Sungai Amazon Brasil. Eceng gondok memiliki kecepatan tumbuh yang tinggi sehingga tumbuhan ini dianggap sebagai gulma yang dapat merusak lingkungan perairan. Eceng gondok dengan mudah menyebar melalui saluran air ke badan air lainnya. Eceng gondok hidup mengapung di air dan kadangkadang berakar dalam tanah. Tingginya sekitar 0,4 - 0,8 meter dan tidak mempunyai batang.

Walaupun Eceng Gondok (Eichhornia crassipes) dianggap sebagai gulma di perairan, sebenarnya ia berperan dalam menangkap polutan logam berat. Rangkaian penelitian seputar kemampuan eceng gondok oleh peneliti Indonesia antara lain oleh Widyanto dan Susilo (1977) [2]. yang melaporkan dalam waktu 24 jam eceng gondok mampu menyerap logam kadmium (Cd), merkuri $(\mathrm{Hg})$, dan nikel (Ni), masing- masing sebesar $1,35 \mathrm{mg} / \mathrm{g}, 1,77 \mathrm{mg} / \mathrm{g}$, dan $1,16 \mathrm{mg} / \mathrm{g}$ bila logam itu tak bercampur. Eceng gondok juga menyerap Cd 1,23 mg/g, Hg 1,88 mg/g dan Ni 0,35 mg/g berat kering apabila logam-logam itu berada dalam keadaan tercampur dengan logam lain. Penelitian lain menyimpulkan logam chrom (Cr) dapat diserap oleh eceng gondok secara maksimal pada $\mathrm{pH}=7$ [3] . Dalam penelitiannya, logam $\mathrm{Cr}$ semula berkadar $15 \mathrm{ppm}$ turun hingga 51,85 persen. Selain dapat menyerap logam berat, eceng gondok dilaporkan juga mampu menyerap residu pestisida.

Sebagian besar masyarakat yang berada di Perumahan Green Tombro, Kota Malang membuang limbah cair hasil aktivitas cuci, mandi, dan dapur langsung ke saluran pembuangan air tanpa diolah terlebih dahulu. Lama - kelamaan, hasil limbah ini mengalami dekomposisi berubah menjadi kehitaman dan menimbulkan bau busuk dan menimbulkan berbagai penyakit. Beberapa penelitian menunjukkan bahwa tanaman air mampu menguraikan limbah cair tersebut, sehingga air limbah buangan menjadi lebih baik. Sebelum limbah dibuang ke saluran pembuangan air, dialirkan ke selokan sampai penampungan di pekarangan rumah, yang ditanami tanaman hias air. Disinilah air limbah ini mengalami proses penguraian. Salah satu alternatif pengolahan limbah cair domestik yaitu dengan cara filtrasi dengan menggunakan media tanaman yang efisien, dan efektif.

\section{METODOLOGI}

\subsection{Pengujian pH Limbah Cair Domestik}

Pada pengujian kualitas limbah cair domestik ini menggunakan lakmus sampai derajat keasaman $(\mathrm{pH})$ air limbah tersebut bersifat netral $(\mathrm{pH}=6-8)$. Apabila air limbah yang telah diolah sudah dikatakan netral, maka air olahan tersebut dapat digunakan kembali dan effluen yang dihasilkan telah memenuhi standar baku mutu limbah domestik yang dapat dibuang ke lingkungan sesuai dengan Keputusan Menteri Negara Lingkungan Hidup No. 112 Tahun 2003 dan dapat digunakan ulang sesuai dengan Peraturan Pemerintah No. 82 Tahun 2001 tentang Pengelolaan Kualitas Air dan Pengendalian Pencemaran Air baku mutu kelas II. 


\subsection{Perhitungan kadar COD (Chemical Oxygen Demand)}

Besarnya nilai COD menggambarkan jumlah oksigen yang dibutuhkan oleh bahan oksidan, misalnya kalium dikhromat $\mathrm{K}_{2} \mathrm{Cr}_{2} \mathrm{O}_{7}$, untuk mengoksidasi bahan-bahan organik yang terdapat dalam air. Uji COD merupakan suatu cara untuk mengetahui jumlah bahan organik yang lebih cepat daripada uji BOD, yaitu berdasarkan reaksi kimia dari suatu bahan oksidan [4].

$$
\mathrm{COD}(\mathrm{mg} / \mathrm{L}) \quad=\frac{(A-B) N F A S \times P}{V \text { sampel }} \times 1000
$$

Keterangan:

$$
\begin{array}{ll}
\text { A } & =\text { ml nitran sampel } \\
\text { B } & =\text { ml titrasi sampel } \\
\text { Vs } & =\text { volume sampel } \\
\text { N Fas } & =\text { Normalitas FAS } \\
\text { P } & =\text { Pengenceran }
\end{array}
$$

\subsection{Perhitungan BOD (Biological Oxygen Demand)}

BOD (Biological Oxygen Demand) atau kebutuhan oksigen biologis adalah jumlah oksigen yang dibutuhkan oleh makrozoobentos aerobic di dalam air lingkungan untuk memecah (mendegredasi) bahan buangan organik yang ada di dalam air lingkungan tersebut. Pembuangan bahan organic melalui proses oksidasi oleh makrozoobentos di dalam air lingkungan adalah proses alamiah yang mudah terjadi apabila air lingkungan mengandung oksigen yang cukup [5].

$$
\mathrm{BOD}(\mathrm{mg} / \mathrm{L})=\frac{A x N F A S \times 8000}{V-4}
$$

Keterangan :

$$
\begin{array}{ll}
\mathrm{A} & =\text { ml nitran sampel } \\
\mathrm{Vt} & =\text { volume total } \\
\mathrm{N} \mathrm{Fas} & =\text { Normalitas FAS }
\end{array}
$$

\subsection{Perencanaan Model berskala Laboratorium}

Perencanaan model berskala laboratorium dengan menggunakan lima buah tong yang bervolume 30 liter air. Diantara lapisan filtrasi pengolahan limbah yang dilakukan secara fisik digunakan untuk mengolah limbah yang mengandung benda padat seperti serat, ampas, lumpur, bulu serta kotoran padat lainnya. Menurut [6] cara ini disebut dengan cara pengolahan limbah secara mekanis yang terdiri dari penyaringan, pengambilan buihnya, pengambangan dan sedimentasi.

\subsection{Lokasi Penelitian}

Lokasi penelitian dilaksanakan di Laboratorium Enviro Hydro, Teknik Sipil Universitas Islam Malang. Kemudian pengambilan sampel limbah cair domestic diperoleh di perumahan Green Tombro Kelurahan Tasikmadu Kecamatan Lowokwaru, Kota Malang. 


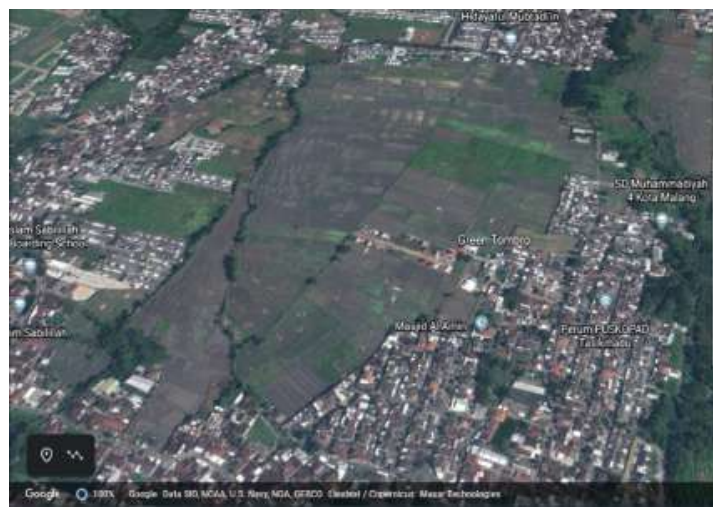

\section{Gambar 1. Lokasi perumahan Green Tombro Tasikmadu Kota Malang.}

\subsection{Metode Analis}

Metode ini memuat cara dan urutan kerja untuk mendapatkan hasil yang sesuai dengan teknologi pengolahan limbah cair agar dapat dimanfaatkan kembali. Metode yang digunakan pada studi ini adalah sebagai berikut:

(1) Melakukan studi literatur;

(2) Melakukan survei pendahuluan;

(3) Menentukan lokasi tinjau dan variabel pencemar;

(4) Melakukan observasi;

(5) Melakukan analisa data dan pembahasan;

(6) Merumuskan kesimpulan.

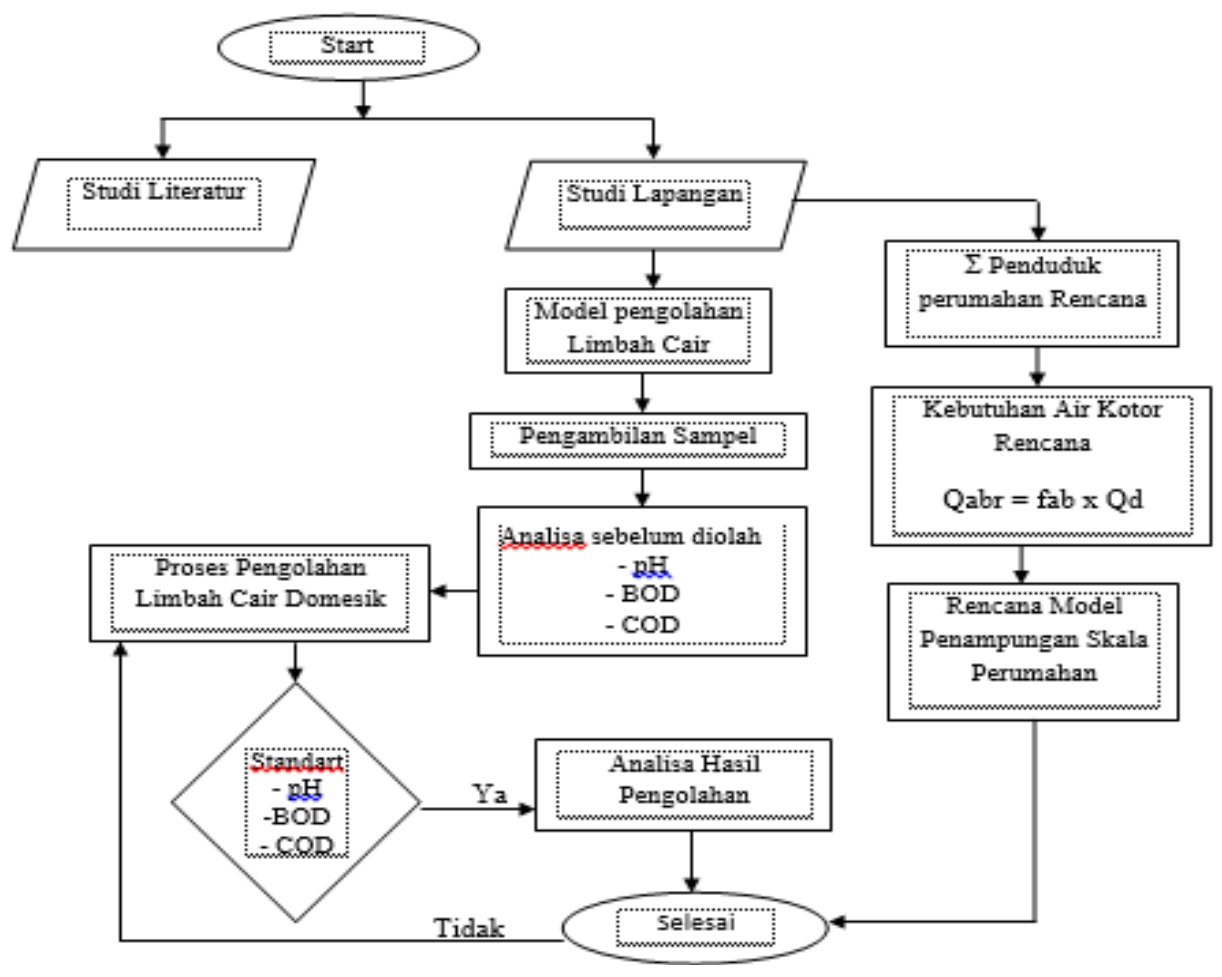

Gambar 2. Flowchart penelitian 


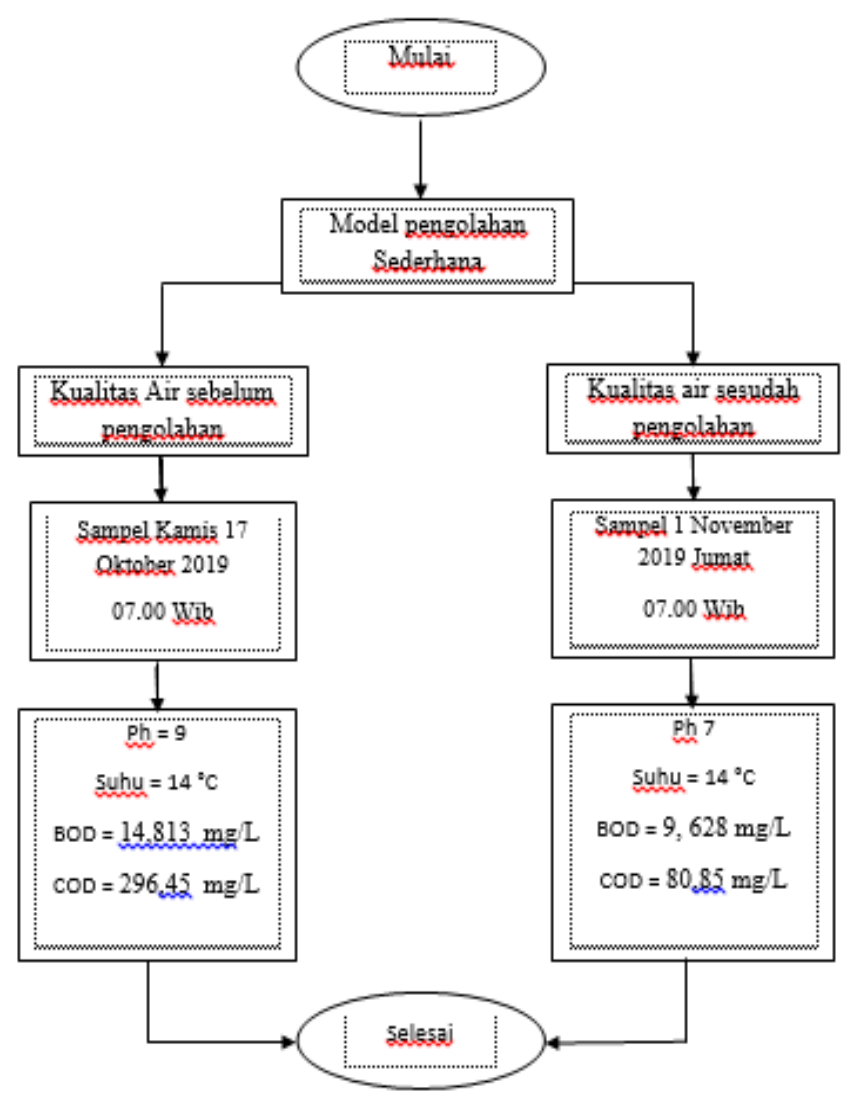

Gambar 3. Skema model pengolahan limbah cair domestik

\section{HASIL DAN PEMBAHASAN}

Pada bagian ini akan dibahas proses filtrasi dan pengolahan limbah cair domestik menjadi air bersih khususnya untuk diaplikasikan pada kebutuhan tanaman irigasi. Adapun alat dan bahan sederhana yang digunakan sebagai media dalam pengolahan limbah cair domestik pada penelitian ini antara lain sebagai berikut:

\section{Alat yang digunakan:}

(1) Pipa PVC ukuran 1/2 inci; (2) 20 botol aqua ukuran $1500 \mathrm{ml}$; (3) Drum berukuran $30 \mathrm{~L}$ untuk menampung limbah cair domestic; (4) Indikator $\mathrm{pH}$ Universal untuk menguji kualitas $\mathrm{pH}$ air.

\section{Bahan yang digunakan:}

(1) Media pasir, kerikil dan koral putih diletakkan pada tong yang satu setinggi $30 \mathrm{~cm}$, tong kedua setinggi $40 \mathrm{~cm}$ dan tong ke tiga setinggi $10 \mathrm{~cm}$; (2) Tanaman eceng gondok (Eichhornia crassipes) sebagai media penyerap polutan limbah cair domestic; (3) Sampel limbah rumah tangga; (4) 2 lembar kain bekas; (5) Sabut kelapa.

\section{Persiapan media proses penelitian ini sebagai berikut:}

(1) Menyiapkan rak kayu untuk menempatkan tong pengolahan limbah cair domestik setinggi $60 \mathrm{~cm}$ untuk penempatan tong yang pertama, sedangkan yang tong yang kedua setinggi $45 \mathrm{~cm}$, tong ketiga $30 \mathrm{~cm}$ dan tong keempat dan kelima setinggi $25 \mathrm{~cm}$, dengan posisi bertingkat;

(2) Tong pertama hanya sebagai penampung limbah cair domestik sebelum memasuki proses filtrasi limbah cair; 
(3) Dasar tong yang kedua berisi material seperti pasir, koral putih, kain bekas, serabut kelapa dan kerikil diurutan paling atas. Tong yang kedua berisi material pasir halus dilapisi kain bekas yang akan menahan pasir agar tidak keatas, kemudian ditambahkan spons agar memaksimalkan penyaringan atau proses filtrasi limbah cair domestic;

(4) Menyediakan tanaman yang mampu menyerap polutan yang terdapat pada limbah cair domestik yaitu tanaman eceng gondok sebagai media perbandingan dari penelitian;

(5) Mengisi penuh tong dengan sampel limbah, yang telah siap untuk dipakai untuk proses filtrasi dan pengolahan limbah cair domestik;

(6) Proses mediasi menggunakan tanaman dilakukan selama 25 hari atau sampai air benar - benar layak atau aman untuk digunakan sebagai kebutuhan air irigasi dan hasil effluen yang memenuhi standar baku mutu limbah domestik yang boleh dibuang ke lingkungan sesuai dengan Keputusan Menteri Negara Lingkungan Hidup No. 112 Tahun 2003 dan dapat digunakan ulang sesuai dengan Peraturan Pemerintah No. 82 Tahun 2001 tentang Pengelolaan Kualitas Air dan Pengendalian Pencemaran Air baku mutu kelas II.

\section{a. Perhitungan kandungan COD pada limbah cair domestik.}

Sebelum pengolahan :

$$
\begin{aligned}
& \operatorname{COD}(\mathrm{mg} / \mathrm{L})=\frac{(\mathrm{A}-\mathrm{B}) \mathrm{N} \mathrm{FAS} \times \mathrm{P}}{\mathrm{V} \mathrm{sampel}} \times 1000 \\
& \operatorname{COD}(\mathrm{mg} / \mathrm{L})=\frac{(4,20-3,65) \times 28 \times 0,0385}{2} \times 1000=296,45 \mathrm{mg} / 1 .
\end{aligned}
$$

Setelah pengolahan :

$$
\begin{aligned}
& \operatorname{COD}(\mathrm{mg} / \mathrm{L})=\frac{(\mathrm{A}-\mathrm{B}) \mathrm{N} \mathrm{FAS} \times \mathrm{P}}{\mathrm{V} \mathrm{sampel}} \times 1000 \\
& \operatorname{COD}(\mathrm{mg} / \mathrm{L})=\frac{(2,50-2,35) \times 28 \times 0,0385}{2} \times 1000=80,85 \mathrm{mg} / \mathrm{l} .
\end{aligned}
$$

\section{b. Perhitungan kandungan BOD pada limbah cair domestik}

$>$ diketahui sebelum pengolahan:

$$
\begin{aligned}
\mathrm{A} & =5 \mathrm{ml} \\
\mathrm{N} & =0,874 \mathrm{ml} \\
\mathrm{V} & =240 \mathrm{ml}
\end{aligned}
$$

$\mathrm{OT}(\mathrm{mg} / \mathrm{L})=\frac{\mathrm{A} \times \mathrm{N} \times 8000}{\mathrm{~V}-4}$

Maka, oksigen terlarut sebelum pengolahan adalah

$\mathrm{OT}(\mathrm{mg} / \mathrm{L})=\frac{5 \times 0,0874 \times 8000}{240-4}=14,813 \mathrm{mg} / \mathrm{l}$

BOD setelah proses pengolahan:

diketahui :

$$
\begin{aligned}
\mathrm{A} & =3,25 \mathrm{ml} \\
\mathrm{N} & =0,874 \mathrm{ml} \\
\mathrm{V} & =240 \mathrm{ml}
\end{aligned}
$$

$$
\mathrm{OT}(\mathrm{mg} / \mathrm{L}) \quad=\frac{\mathrm{A} \times \mathrm{N} \times 8000}{\mathrm{~V}-4}
$$

Sehingga,

OT $(\mathrm{mg} / \mathrm{L}) \quad=\frac{3,25 \times 0,0874 \times 8000}{240-4}=9,628 \mathrm{mg} / 1$ 
Berdasarkan hasil perhitungan kadar $\mathrm{pH}$, COD dan BOD yang terkandung pada limbah cair domestik setelah pengujian laboratorium selama 25 hari $\mathrm{pH}$ sebelum pengolahan adalah 9 dimana batas $\mathrm{pH}$ aman untuk kebutuhan tanaman irigasi antara $\mathrm{pH}=6-8$. Kondisi $\mathrm{pH}$ dikatakan tidak aman, maka air limbah tersebut tidak layak untuk kebutuhan tanaman irigasi sebab bersifat basa. Limbah cair domestik yang bersifat basa disebabkan aktifitas masyarakat setempat yang menggunakan detergen untuk mencuci. Kadar awal COD sebelum limbah diolah sebesar 296,45 mg/l dimana kadar tersebut melebihi ketentuan batas baku mutu air limbah cair domestik. Kemudian setelah limbah cair tersebut diolah, hasilnya menjadi $80,85 \mathrm{mg} / \mathrm{l}$.

Kadar awal BOD sebelum terjadi pengolahan sebesar $14,813 \mathrm{mg} / \mathrm{l}$, sedangkan sesudah terjadi pengolahan menjadi 9,628 mg/l yang berarti sudah memenuhi ketentuan baku mutu air limbah cair domestik yang mengacu pada peraturan Menterti Lingkungan Hidup dan Kehutanan Indonesia No. P.68/Menlhk/Setjen/Kum.1/8/2016. Proses penyerapan zat-zat yang terdapat dalam limbah cair domestic dilakukan oleh akar-akar tanaman eceng gondok dengan jaringan meristem. Hal ini terjadi karena adanya gaya tarik-menarik oleh molekul-molekul air yang ada pada tumbuhan tersebut. Zat-zat yang telah diserap oleh akar akan masuk ke batang melalui pembuluh pengangkut (xilem0 yang kemudian akan diteruskan ke daun. Pertumbuhan tanaman yang semakin besar mengakibatkan luas permukaan dari akar untuk menyerap polutan yang ada juga semakin besar dibandingkan dengan tumbuhan yang berukuran kecil.

\section{c. Perencanaan model pengolahan limbah cair domestik}

Dari hasil hitungan debit rencana adalah $30,6 \mathrm{~m}^{3} /$ hari. Rencana volume pada tampungan pertama yaitu $10,2 \mathrm{~m}^{3}$. Hasil yang diperoleh dari proses pengolahan limbah cair domestik dengan tanaman eceng gondok diperoleh $1,40 \mathrm{~m}^{3}$. Proses pengolahan ini diperlukan tanaman eceng gondok sebanyak 120 tanaman. Kemudian volume hasil akhir pengolahan limbah cair domestik adalah $690 \mathrm{~m}^{3}$.

Hasil perhitungan kebutuhan debit air kotor untuk 34 unit rumah adalah 1,275 $\mathrm{m}^{3} / \mathrm{jam}$. Kemudian akan dilanjutkan ke saluran pipa pembuangan yang akan mengalir ke penampungan terakhir pada Penampungan limbah cair domestik untuk perumahan Green Tombro. Selanjutnya hasil penampungan yang sudah diolah, dapat digunakan untuk pemanfaatan pemenuhan air irigasi atau sebagai air untuk menyiram tamanaman pada taman di Perumahan Green Tombro, Kota Malang.

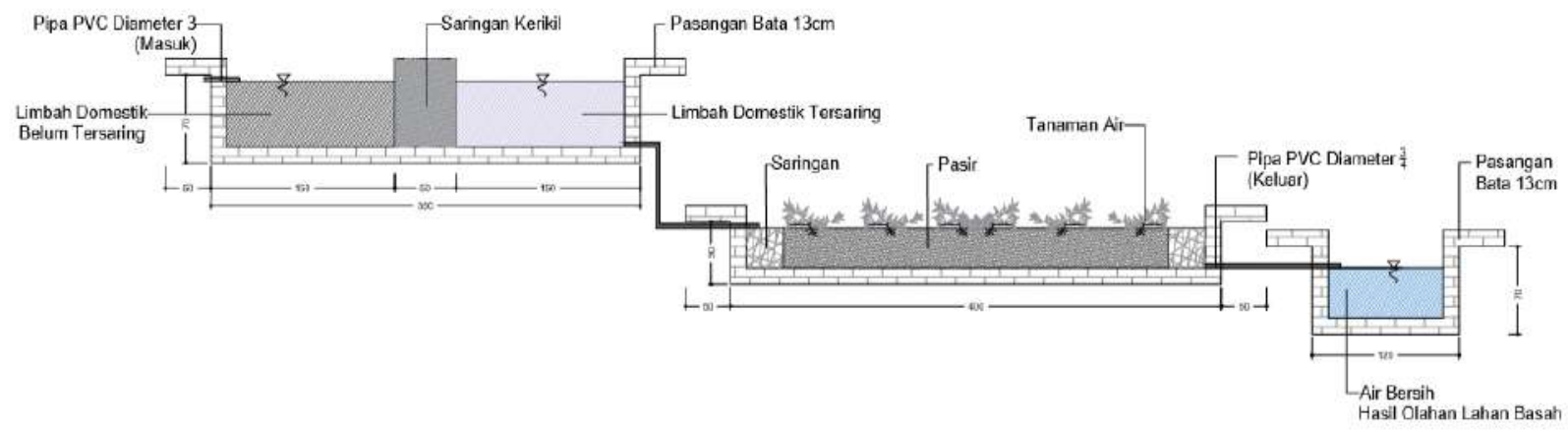

Gambar 4. Sketsa tempat penampungan dan pengolahan limbah cair domestik 


\section{KESIMPULAN}

Karakteristik limbah cair domestik sebelum terjadi pengolahan di Perumahan Green Tombro Kota Malang yaitu memiliki $\mathrm{pH}=9$, kandungan COD sebesar 296,45 mg/l, dan kandungan BOD sebesar $14,813 \mathrm{mg} / \mathrm{l}$. Sedangkan setelah mengalami proses pengolahan, karakteristik limbah cair domestik memiliki $\mathrm{pH}=7$ (dikatakan netral), kandungan COD sebesar 296,45 mg/1 dan kandungan BOD sebesar $80,85 \mathrm{mg} / \mathrm{l}$. Sistem pengolahan untuk limbah cair domestik yaitu dengan perlakuan secara filtrasi, kemudian dilanjutkan dengan pengolahan menggunakan tanaman eceng gondok dan diakhiri dengan desinfeksi oleh sinar matahari sehingga dapat menghasilkan air yang memenuhi standar baku mutu limbah cair domestik yang dapat dibuang ke badan air atau dapat dimanfaatkan kembali untuk tanaman sesuai dengan Keputusan Menteri Negara Lingkungan Hidup No. 112 Tahun 2003 dan dapat digunakan ulang sesuai dengan Peraturan Pemerintah No. 82 Tahun 2001 tentang Pengelolaan Kualitas Air dan Pengendalian Pencemaran Air baku mutu kelas II.

\section{DAFTAR PUSTAKA}

[1] Suripin, (2002). Pelestarian Sumberdaya Tanah dan Air, Penerbit: ANDI, Yogyakarta.

[2] Widyanto, L., dan Susilo, (1977). Eceng Gondok sebagai Penyerap Air, Penerbit: Tropikal Pest Biologi Program SEAMEO-BIOTROP, Bogor.

[3] Lubis, E., dan Y. Sofyan, (1986). Penyerapan Cr oleh Eceng Gondok dari Larutan Media Tanam Menggunakan Peru-nut Cr-51. Penerbit: Majalah BATAN, Jakarta.

[4] Fardiaz, S. (1987). Mikrobiologi Pangan I. Penerbit; Jurusan Teknologi Pangan dan Gizi Fakultas Teknologi Pertanian Institut Pertanian Bogor, Bogor.

[5] Wardhana, A.W., (1995). Dampak Pencemaran Lingkungan Edisi II, hal. 35. Penerbit: Andi Offset.

[6] Mahida, U.N., (1986). Pencemaran Air dan Pemanfaatan Limbah Industry. Penerbit: CV. Rajawali, Jakarta. 